\title{
LiteraCAp: uma proposta, vários olhares
}

\author{
Rita de Cássia Cavalcante \\ Gabriela Pirotti Pereira** \\ Freya Neander Souza de Souza ${ }^{* *}$
}

Resumo: O LiteraCAp vem sendo desenvolvido desde 2008 junto aos alunos do $2^{\circ}$ ano do Ensino Médio do Colégio de Aplicação da UFRGS. Projeto de Educação a Distância, utiliza as diversas redes sociais disponíveis na 'web', visando à extensão dos estudos curriculares de Língua Portuguesa e Literatura, à produção de discursos autorais e ao compartilhamento responsável das informações disponíveis na internet. O conteúdo elaborado pelos participantes tem sido objeto de investigação da Equipe de Trabalho vinculada à ação, formada por alunos e professores da escola e por estudantes de graduação da UFRGS. Palavras-chave: Novas tecnologias; TICs; Redes Sociais; Leitura e Escrita.

Abstract: LiteraCAp is being developed since 2008 with students of the 2nd year of High School at Colégio de Aplicação of UFRGS. It's a project of Distance Education, and uses the various social networks available on 'the web', aiming at the enlargement of Portuguese Language and Literature curricular

\footnotetext{
* Professora de Língua Portuguesa e Literatura do CAp/UFRGS. Mestre em Literatura Brasileira. E-mail: ritaccav@gmail.com

** Estudante do segundo ano do Ensino Médio do CAp/UFRGS e bolsista do Projeto Primeira Ciência, do CNPq, em 2011. E-mail: gabipirotti@hotmail.com

*** Estudante do curso de Letras da Universidade Federal do Rio Grande do Sul e exaluna do CAp/UFRGS, onde atuou como bolsista do Projeto Primeira Ciência, do CNPq, em 2011. E-mail: freyans@gmail.com
} 
studies, at the production of authorial discourses and at the responsible sharing of information available on internet. All the contents produced by the participants became researching subject for the working group linked to the project, and this group consists of students and teachers from Aplicação and under graduating students from UFRGS.

Keywords: New Technologies; TICs; Social Networks; Reading and Writing.

Como professora de Língua Portuguesa e de Literatura, ao longo da minha prática docente, tenho observado sempre com olhos atentos os recursos oferecidos pelas novas tecnologias de informação e comunicação a fim de tornar as aulas mais próximas da realidade dos adolescentes dessa geração, conectada à internet e com acesso à informação com uma velocidade até então desconhecida pela maioria de nós, seus professores.

Considerando uma prática que tem por objetivo desenvolver sujeitos - autores e leitores - críticos e que sejam capazes de reconhecerem a si e ao mundo na e por meio da Língua e da Literatura, comecei a testar primeiramente a escritura em blogues, buscando criar um espaço em que, além da expressão, eles pudessem também observar a produção alheia e desenvolver textos críticos, na medida em que comentassem a opinião de seus pares. Com o tempo, os blogues, embora oferecessem novos recursos, como a inserção de vídeos, para o público com o qual trabalho, não atenderam mais às expectativas iniciais, foram tendo cada vez menos visitações, e foram substituídos pela dinâmica da Rede social.

Minha primeira experiência com o Orkut limitou-se à criação de uma comunidade que, ainda que desde sempre tivesse como objetivo explorar o potencial crítico dos alunos, limitou-se a uma espécie de agenda virtual, um mural para troca de informaçôes sobre datas de avaliações e combinações sobre os critérios para o desenvolvimento dos trabalhos. Tentei criar 
comunidades temáticas, vinculadas aos assuntos desenvolvidos em aula e acrescentar outras comunidades já existentes. Ainda não havia encontrado aquilo que esperava, entretanto.

Iniciei, então, um projeto de pesquisa com os monitores de ensino Kauan Negri e Giselle Bayan testando sites que hospedassem a criação de redes personalizadas ${ }^{1}$. Utilizamos o NING, posteriormente o Grou.ps, que renderam momentos de grande produção e troca por parte dos alunos, mas precisaram ser abandonadas quando os servidores passaram a exigir pagamento para acesso aos recursos (como a inclusão de novos usuários, por exemplo), o que não atendia aos meus propósitos como professora de escola pública.

O passo seguinte foi transformar o projeto numa ação que fornecesse instrumentos de pesquisa também aos alunos do Ensino Médio, aos próprios usuários, e a outros professores. Foi quando o LiteraCAp foi registrado como pesquisa, vinculada ao $\mathrm{CNPq}$, que concedeu no ano de 2011 bolsas PIBIC-EM às alunas do terceiro e primeiro ano do Ensino Médio da Escola, respectivamente, Freya de Souza e Gabriela Pirotti. Os resultados das pesquisas é que apontaram para o Facebook (testamos também o Twitter, o Tumblr, Google + e Docs, PBworks, entre outras). Além disso, as pesquisas ${ }^{2}$ realizadas pelos alunos contribuíram com importantes dados sobre o comportamento dos alunos usuários como autores e leitores.

Em função do ambiente, que permite, principalmente, $\mathrm{o}$ registro de opiniões (seja via postagens, comentários - sempre estimulados - seja em forma de "curtir" ou "compartilhar") se dá de forma mais dinâmica. Os alunos reconhecem também como seu o espaço e aprendem com o tempo que há um objetivo

Foi quando o espaço foi intitulado LiteraCAp, nome que se mantém até hoje.

As pesquisas realizadas pelas alunas foram: "Hábitos de leitura dos alunos do Ensino Médio do Colégio de Aplicação" e "Alunos autores na Rede LiteraCAp", de Gabriela Pirotti e Freya de Souza, respectivamente, apresentados no Salão de Iniciação Científica da UFRGS, em 2011. O projeto ainda é vinculado ao Programa Primeira Ciência, do CNPq, que, em 2012, concede - desde março- bolsa à aluna Carolina Dall'Agnol. 
pedagógico por trás da existência do grupo. Tem sido prática, como nossa escola faz parte do programa "Um Computador por Aluno”, do MEC, utilizar o LiteraCAp como referência não só para troca de informações sobre os trabalhos, como ocorria no Orkut, mas também para a troca de opiniões, para o compartilhamento de material que complemente as discussões surgidas em sala de aula ou como mote para que sejam geradas novas discussões relacionadas aos temas que permeiam os estudos de Língua Portuguesa e de Literatura.

Além disso, os alunos têm se apropriado cada vez mais do espaço, tornando-o ao mesmo tempo, coletivo e particular, registrando citações de obras que os representem, vídeos que falem sobre o universo da leitura e sobre o seu olhar acerca do universo jovem. Diante da participação dos jovens e dando conta de um projeto de ensino integrado, em rede, atendendo à proposta pedagógica da equipe do Ensino Médio do Colégio de Aplicação, outros professores, de distintas áreas do conhecimento, têm usufruído do espaço, também interagindo - sempre tendo em vista a proposta de promover a leitura, a escritura em sujeitos críticos, autônomos e sociais, que percebam o valor (e por que não dizer, o poder) da palavra - que não é somente virtual, uma vez que é representação de pessoas de verdade, que escrevem-se naquele espaço, doando "o que estão pensando".

A proposta de utilização do Facebook ${ }^{3}$ constrói-se, assim, a partir da criação de um grupo temático, cujos objetivos e normas de postagem e convivência devem ser claros (considerando que a prática leva sempre também à construção de sujeitos sociais). Como proposta inicial, sugere-se a postagem de textos de diferentes naturezas (estabelecendo intertextualidade, e hiperlinks) que promovam a reflexão sobre um determinado assunto, que não deve esgotar-se no ambiente virtual, mas estabelecer diálogo com a sala de aula, que, por sua vez, retornará ao ambiente virtual,

3 O Facebook permite usuários maiores do que 13 anos de idade e disponibiliza aos professores um guia de utilização com propostas educacionais: http://facebookforeducators.org/educators-guide 
tornando todos os espaços integrados na proposta de educar para a vida, o que inclui também educar para a tecnologia.

Muito ainda há o que ser investigado, especialmente porque é necessário ter sempre em vista que o ambiente virtual não é rígido e apresentará o perfil conforme for o de seus usuários. Assim, o grande desafio - e ele é diário - de manter o espaço dinâmico e interessante, é, por vezes, renovar-se também como profissional - que precisa desconstruir suas próprias verdades para conhecer a verdade inovadora do outro, aquele que chamamos de aprendiz.

\section{Hábitos de leitura dos alunos de Ensino Médio do Colégio de Aplicação 4}

Quando iniciei minha bolsa de estudos, oferecida pelo $\mathrm{CNPq}$, a Rede LiteraCAp já estava em plena atividade. Era, então, uma página no Grou.ps, servidor que hospedava redes sociais de pequeno porte. Inicialmente a pesquisa consistiu em aprender como funcionava o LiteraCAp e qual sua proposta didática, já que eu nunca havia utilizado esse espaço, pois era aluna do primeiro ano do Ensino Médio no Colégio de Aplicação. O próximo passo foi atender aos alunos que encontravam dificuldade em utilizar a rede, orientando-os, junto com minha colega bolsista Freya de Souza.

Parte das nossas atividades semanais era buscar notícias, vídeos, enfim, novidades que pudessem prender o interesse dos alunos usuários do LiteraCAp. A intenção era trazer discussões para o grupo, estimular a argumentação e a crítica. Mas, não recebemos muitas respostas dos alunos, no início.

Nossa atividade seguinte foi ler os "Diários de leitura" 5 , postados na Rede ou no Google Docs pelos alunos do segundo ano

\footnotetext{
Relato de Gabriela Pirotti Pereira.

5 Os Diários de Leitura são um instrumento utilizado nas aulas de Literatura e Língua Portuguesa da Prof ${ }^{a}$. Rita Cavalcante com o objetivo de registro autoral sobre as
} 
do Ensino Médio. Com base nesses textos, analisávamos a identidade do aluno como leitor e os seus movimentos de autoria na escrita. O tema dos diários era livre, e poderia tratar de qualquer romance, conto, ou outra forma de literatura que interessasse, além de outras leituras que os alunos realizassem por conta ou não das orientações escolares. Com o passar do tempo, minhas observações voltaram-se para o que os alunos estavam lendo, e essas análises deram origem à pesquisa que desenvolvi ao longo do ano: "Hábitos de leitura dos alunos do Ensino Médio do Colégio de Aplicação".

Para me aprofundar no assunto, elaborei, com o auxílio da professora Rita Cavalcante, um questionário com questões objetivas que intencionavam verificar que tipo de texto os estudantes preferiam bem como diversos aspectos sobre seus hábitos de leitura. Entre as perguntas realizadas, destaco:

- Com que frequência você lê livros? (referindo-se a frequência)

- Você está lendo algum livro agora?

- Por que você lê livros?

- Onde você lê geralmente?

- Que fatores determinam a sua escolha por um livro?

- Que tipo de livro você prefere ler?

- Como você registra suas impressões?

- Você acredita que as leituras sugeridas pela escola são importantes?

O questionário foi aplicado primeiro virtualmente, enviado por e-mail, para os alunos de apenas uma das turmas de segundo ano. A reunião desses primeiros dados mostrou que $100 \%$ dos alunos tinha preferência por ler obras impressas, e não digitalizadas. Foi possível verificar que 67\% dos estudantes dizia não

impressões de leitura. Cada aluno deve desenvolver semanalmente textos que deem conta de suas leituras, não somente as literárias, buscando construir, além de uma sistematização, reflexão sobre sua identidade como sujeitos autores de textos em Língua Portuguesa. 
registrar suas opiniões sobre obras literárias por escrito, embora mantivessem registros semanais de leitura na Rede LiteraCAp. O questionário também mostrou que $42 \%$ dos alunos não liam somente por obrigação escolar, mas também por prazer.

Os resultados parciais da pesquisa, em sua maioria, coincidiram com os obtidos mais tarde, quando aplicamos o questionário aos alunos das três turmas de segundo ano. Foi possível analisar que, 69\% dos alunos lia tanto por obrigação escolar quanto por prazer. $76 \%$ disse preferir ler obras impressas às versões virtuais dos mesmos livros. Dessa vez, $47 \%$ dos alunos disse não registar suas impressões por escrito, e apenas 17\% responderam que as registravam em arquivos virtuais compartilhados.

Esses resultados nos levaram a uma nova questão: Por que os alunos acreditavam que não estão registrando suas impressões sobre o que liam, se o faziam regularmente na rede social? - que poderá ser verificada na continuidade da pesquisa. Por enquanto, novos espaços continuam sendo testados, entre eles o Facebook, conhecido e utilizado por quase todos os usuários da Rede.

Em 2012, participo das atividades no LiteraCAp não mais como bolsista, mas como aluna. Devo dizer que a pesquisa me mostrou a importância desse meio para o estudo da Língua Portuguesa e Literatura, o quão rica é a troca de experiências e as discussões que surgem entre os colegas e os professores que participam do ambiente. A oportunidade de participar desse projeto de pesquisa trouxe-me uma visão nova sobre como novos espaços expandem as opções e também nossos horizontes.

\section{Alunos autores na rede LiteraCAp}

A pesquisa sobre os "Alunos autores na rede LiteraCAp" foi se moldando aos poucos; em um primeiro momento o objetivo era reconhecer e estudar as ferramentas que o site Grou.ps oferecia. Ao mesmo tempo, a proposta era acompanhar tudo aquilo

6 Relato de Freya Neander Souza de Souza. 
que os alunos escrevessem "Diários de Leitura" ou postassem em suas wikis (recurso disponível em nosso primeiro ambiente). Cada postagem deveria conter informações sobre os enredos, mas também textos argumentativos sobre as leituras realizadas.

Com o início do ano letivo e a apresentação deste novo espaço para os alunos, foi possível começar a planejar os projetos, por meio do estudo dos textos produzidos e da interação virtual com os alunos através de fóruns de discussões. Este novo olhar foi o ponto inicial do projeto, pois a área da pesquisa já estava determinada, mas não os caminhos que cada pesquisadora, alunas do Ensino Médio, seguiriam. Ele foi escolhido a partir do modo como as observaçôes e os relatos das leituras eram feitas, de modo processual.

Como o público-alvo era formado por adolescentes, buscamos publicações e ferramentas que os interessasse e lhe chamasse a atenção, o que não foi bem recebido pelo grupo, inicialmente. Apesar de todas as ferramentas que o site oferecia, os alunos se voltaram em sua grande maioria para as wikis, nas quais os "Diários de Leitura" eram postados. Pelo fato de muitos alunos apresentarem dificuldades de utilizar o site foi preciso criar um manual de instruções, e talvez tenha sido este o motivo de os alunos não utilizarem as outras ferramentas que lhes eram oferecidas.

Por não ter tido uma grande aceitação e como um dos objetivos do projeto era observar como os alunos se comportavam em diferentes ambientes virtuais, migramos a rede LiteraCAp para o Google Docs. Um ambiente mais reservado, que garantiria que apenas pessoas selecionados - $\mathrm{o}(\mathrm{a})$ aluno(a), a professora e as bolsistas - poderiam ter acesso aos textos produzidos. Espaço em que, teoricamente, os alunos se sentiriam mais à vontade para escrever, sem receio de serem avaliados pelos colegas, seus pensamentos e reflexões. Entretanto, passado um bimestre, o padrão de produção continuou o mesmo.

No último bimestre letivo migramos, novamente, a localização do LiteraCAp que passou a ser utilizado no Facebook; uma rede social em que a grande maioria dos estudantes possuía 
cadastro, e que, por sua vez, utilizava diariamente. Foi o que aumentou a popularidade do LiteraCAp e a interação entre os alunos, com um aumento de participação expressivo. Tínhamos achado, finalmente, nosso lugar no mundo virtual.

O que chamou nossa atenção, contudo, foi o fato de que os estilos de escrita pouco mudaram. Os alunos continuaram escrevendo da mesma forma, não importando o ambiente em que estavam. Eles produziram, em sua maioria, textos narrativos e descritivos e, poucas vezes, argumentativos, como vemos no gráfico abaixo, elaborado com base na análise de suas postagens no período:

Gráfico 1:

\section{Tipos de texto}

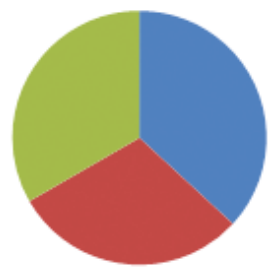

n Narrativo

Descritivo

argumentativo textos ${ }^{7}$ :

Para ilustrar, apresentamos a segui alguns exemplos de

Argumentativo

"percebi a grande polêmica que os livros de Paulo Coelho geram, pois como Zezé afirmava eu também vi que ao longo da minha jornada escolar nunca em nenhuma lista de leituras obrigatórias tinha um título deste escritor que já vendeu milhões e milhões de exemplares de livros.”

Observação: Como vemos neste exemplo, o(a) autor(a) reflete sobre sua leitura, fazendo conexôes com a sua vida e com o mundo a sua volta.

7 Os textos foram transcritos tal qual foram registrados na rede. 


\section{Descritivo}

"Mim e Daniel tem um caso. A história começa com um roubo na escola, e Lucas é acusado e expulso da escola. Daniel também recebe uma carta de seu pai, mas não tem coragem de abri-lá.” Observação: Percebe-se neste trecho que o(a) aluno(a) descreve sua leitura e não elabora reflexões sobre o que leu.

\section{Narrativo}

"Como Bruno ficou surpreso e cheio de dúvidas com o que ele viu atravez da janela, foi até seu pai perguntar quem eram aquelas pessoas e o que elas faziam ali e para reclamar que não estava gostando de Haja-Vista, pois não tinha nada para fazer e ele detestava o lugar onde morava, seu pai fez rodeios e rodeios e no fim só disse que Bruno deveria gostar de onde estavam morando, pois era ele, seu pai, quem mandava em tudo e que Bruno deveria obedecer, nessa parte mostra o quanto os pais madavam nos filhos e eles não podiam fazer e nem falar nada contra... Estou gostando MUITO do livro :D"

Observação: $\mathrm{O}$ escritor(a) conta a história e apesar de falar que está gostando da história, ele(a) não fala do que gosta em especial, o que chamou sua atenção. $\mathrm{O}$ autor do texto, portanto, não desenvolve a questão.

Comparando textos postados nos diversos ambientes, foi possível perceber que os alunos (em sua maioria) continuaram escrevendo da mesma forma. Boa parte das produções possuiu natureza descritiva ou narrativa, dando conta apenas das informações sobre as leituras, porém sem movimento crítico ou argumentativo, conforme previa a proposta pedagógica e o trabalho realizado em sala de aula. Pareceu-nos que esse fato ilustrava justamente a geração que se constrói a partir de um bombardeio de informação pronta e fragmentada, que também caracteriza o universo virtual. Em poucos casos havia a preocupação com a correção linguística. 
Através desta pesquisa aproximamos os alunos do universo literário, da força da palavra. Eles puderam refletir sobre como a visão de mundo, que lhes é imposta, influencia em sua autoria, apesar de esta reflexão ter sido feita apenas no final da pesquisa. O Facebook, como percebemos, foi o grande motivador destas conclusões, e a ferramenta mais eficaz naquilo que se refere à fluência da comunicação.

Atualmente o LiteraCAp tem recebido mais discussões e percebe-se mais assiduidade dos alunos em relação ao grupo anterior. As postagens tornam-se algo (de certa forma) instantâneo, como as postadas em seus murais pessoais.

É possível que em um futuro próximo esta não possa ser a única alternativa, pois para aproximar a juventude da leitura é preciso estar em sintonia com as redes sociais em voga, as que arrecadam mais usuários a cada dia. Será preciso que a rede se mantenha conectada àquilo que é atual e dinâmico, como a Língua Portuguesa, como a Literatura. A prática do LiteraCAp tem rompido com os discursos nos bancos escolares de que a Língua Portuguesa e a Literatura são complicadas e inacessíveis, "bichos de sete cabeças". Na verdade, as postagens no LiteraCAp têm evidenciado que tais disciplinas são resultado dos seus usuários, agora também virtuais.

\section{Muitos olhares, muitos discursos}

Layout do LiteraCAp, criado por Kauan Negri, no ano de 2009, no Grou.ps. 


\section{LITERACAP}

\section{LITERATURA, CIMEMA, ARTES, POESIA} E PAPO FORA.

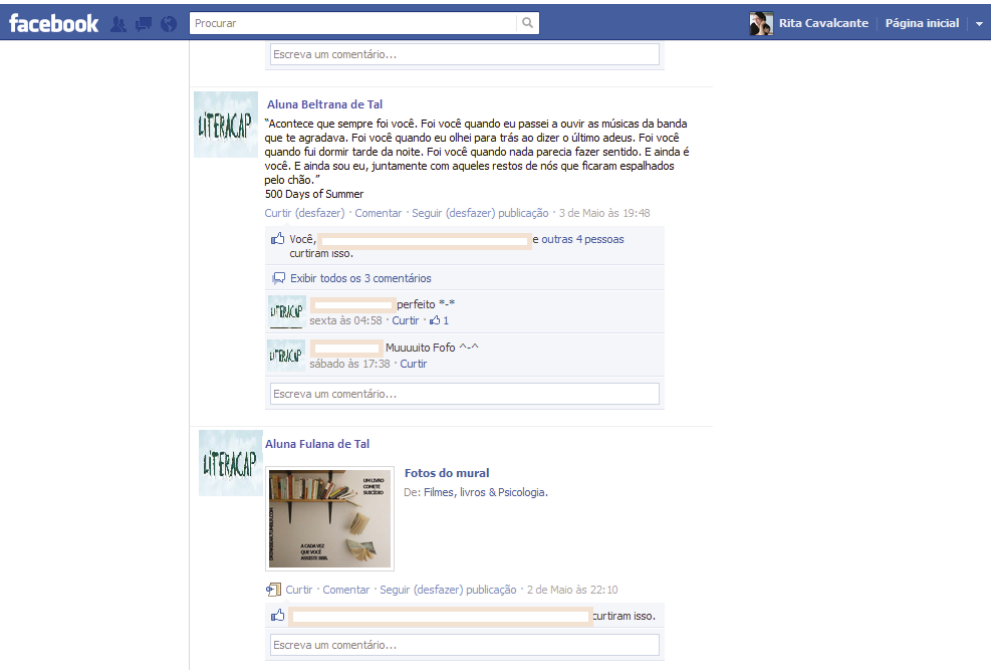

LiteraCAp em seu atual formato, no Facebook. ${ }^{8}$

8 Os nomes e imagens dos alunos foram omitidos. A cópia refere-se à postagens realizadas no último mês. 


\section{Conclusões}

A Rede LiteraCAp mostrou-se, assim, mais do que como um simples ambiente virtual a serviço do ensino de Língua Portuguesa e da Literatura. Ultrapassou os objetivos iniciais do projeto, aqueles que buscavam, de modo geral, investigar na web novos recursos nas Tecnologias de Informação e de Comunicação que tornassem as aulas mais interessantes. Talvez porque reúna um número ilimitado de olhares e de discursos, que dão conta não somente do universo da escola, mas também daquilo que nos constrói como sujeitos conscientes de estar no mundo, talvez porque nos represente como falantes e produtores desse organismo, sempre em formação, que é a Língua Portuguesa. Talvez porque nos projete além dos perfis elaborados das redes sociais, recuperando aqueles que existem além da tela. Talvez, simplesmente, porque nos compartilhe, nos faça, ao mesmo tempo, leitores e autores das subjetividades - as nossas, as dos nossos pares: alunos, ex-alunos, professores, pais. 